\title{
MANEJO DA ADUBAÇÃO NITROGENADA NA CULTURA DA CANOLA
}

\section{ROBERTO WEBBER PUHL ${ }^{1}$, JIMMY WALTER RASCHE-ALVAREZ ${ }^{2}$}

\author{
${ }^{1}$ Universidad Nacional del Este, Ciudad del Este/Paraguai, puhl373@gmail.com, ${ }^{2}$ Universidad Nacional de Asunción, \\ Asunción/Paraguai, jwrasche@yahoo.com.ar
}

RESUMO. Atualmente não existe recomendação de fertilização nitrogenada na canola no Paraguai. O objetivo foi verificar o efeito do manejo da adubação nitrogenada na cultura de canola. Foi implantado um experimento com 5 tratamentos que consistiram em diferentes doses e épocas de aplicação de $\mathrm{N}$ na cultura da canola T1: $0 \mathrm{~kg}$ de $\mathrm{N} \mathrm{ha}^{-1}$; T2: $15 \mathrm{~kg}$ de $\mathrm{N} \mathrm{ha}^{-}$ ${ }^{1}$ na semeadura; T3: $15 \mathrm{~kg}$ de $\mathrm{N} \mathrm{ha}^{-1}$ na semeadura, $46 \mathrm{~kg}$ de $\mathrm{N} \mathrm{ha}^{-1}$ no início da roseta; $\mathrm{T} 4: 15$ $\mathrm{kg}$ de $\mathrm{N} \mathrm{ha}^{-1}$ na semeadura e $46 \mathrm{~kg}$ de $\mathrm{N}^{-1}$ na roseta e; T5: $15 \mathrm{~kg}^{-1 e} \mathrm{~N} \mathrm{ha}^{-1}$ na semeadura, 23 $\mathrm{kg}$ de $\mathrm{N} \mathrm{ha}^{-1}$ no início de roseta e $23 \mathrm{~kg}_{\text {de }} \mathrm{N} \mathrm{ha}^{-1}$ na floração, com quatro repetições. $\mathrm{O}$ delineamento experimental utilizado foi de blocos ao acaso com quatro repetições. Foi determinada altura de planta aos 60 dias após a semeadura e no final de ciclo, o número de síliquas por planta, rendimento de grãos e massa de 1000 grãos. A aplicação de $\mathrm{N}$ produziu efeito significativo em todas as variáveis analisadas, com exceção da massa de mil grãos. $\mathrm{O}$ número de síliquas por planta passou de 86 no T1, para 252 no T5 e o rendimento variou de $607 \mathrm{~kg} \mathrm{ha}^{-1}$ no T1 a $1808 \mathrm{~kg} \mathrm{ha}^{-1}$ no T5, havendo correlação entre estas variáveis. A aplicação de $\mathrm{N}$ aumentou o rendimento de grãos de canola, propiciando maior rendimento quando aplicado o $\mathrm{N}$ na base e em cobertura parceladamente.

PALAVRA CHAVE: Brassica napus, nitrogênio, doses, épocas.

\section{RATE AND TIME OF NITROGEN FERTILIZER APPLICATION ON THE CANOLA CROP}

\begin{abstract}
Currently, there is no nitrogen fertilizer recommendation for the canola crop in Paraguay. The objective of the study was to investigate the effect of $\mathrm{N}$ fertilizer application at different rates and times on yield of canola crop. The treatments consisted of different rates and $\mathrm{N}$ application times in the canola crop: $\mathrm{T} 1-0 \mathrm{~kg}$ of $\mathrm{N} \mathrm{ha}^{-1}$ (control); $\mathrm{T} 2-15 \mathrm{~kg}^{-1} \mathrm{~N} \mathrm{ha}^{-1}$ at sowing; T3 - $15 \mathrm{~kg}$ of N ha ${ }^{-1}$ at sowing and $46 \mathrm{~kg} \mathrm{~N} h a^{-1}$ at the beginning of the rosette stage; $\mathrm{T} 4-15 \mathrm{~kg} \mathrm{~N}^{-1}$ at sowing and $46 \mathrm{~kg} \mathrm{~N} \mathrm{ha}^{-1}$ at the rosette stage; $\mathrm{T} 5-15 \mathrm{~kg}^{-1} \mathrm{~N} \mathrm{ha}^{-1}$ at sowing, $23 \mathrm{~kg} \mathrm{~N} \mathrm{ha}^{-1}$ at the early rosette and $23 \mathrm{~kg} \mathrm{~N} \mathrm{ha}^{-1}$ at flowering, with four replications. Treatments were arranged in a randomized block design with four replications. Plant height was determined at 60 days after sowing and at the end of cycle, the number of seedpods per plant, grain yield and thousand grain mass. The $\mathrm{N}$ application significantly affected all variables, except for the thousand grain mass. The number of seedpods per plant increased from 86 in T1 to 252 in T5 and in the grain yield from $607 \mathrm{~kg} \mathrm{ha}^{-1}$ in T1 to $1808 \mathrm{~kg}$ $\mathrm{ha}^{-1}$ in $\mathrm{T} 5$, with correlation between these variables. The $\mathrm{N}$ application increased the grain yield of canola, resulting in a higher yield when $\mathrm{N}$ was applied in the sowing and in topdressing. The best way to $\mathrm{N}$ application in top-dressing split in two times.
\end{abstract}

KEY WORDS: Brassica napus, nitrogen, rates, times. 


\section{INTRODUÇÃO}

A canola (Brassica napus L.) é uma cultura importante no sul-leste da Região Oriental do Paraguai, no entanto, ainda não existe recomendação oficial sobre fertilização nitrogenada na canola. A área semeada de canola em 2013 foi de 46.775 ha, com rendimento médio de grãos, de $1.112 \mathrm{~kg} \mathrm{ha}^{-1}$ (INBIO, 2013). A canola nessa região se destaca como uma excelente alternativa econômica para uso no sistema de rotação de culturas, semeado principalmente após, a cultura da soja, substituindo o trigo, quebrando assim, o ciclo de doenças que afetam este cereal. A expansão da canola no sul-este da Região Oriental do Paraguai é favorável, devido a que esta região apresenta condições adequadas à cultura, pois a canola è exigente em disponibilidade de luz, água, insolação e temperatura (DALMAGO et al., 2013).

A canola é bastante sensível ao déficit hídrico (BILIBIO et al., 2011; SANCHES et al., 2014), necessitando aproximadamente de $56 \mathrm{~cm}$ de lâmina d'água, bem distribuídas durante o ciclo, para maximizar á produtividade (INZUNZA-IBARRA et al., 2014).

Entre os componentes do rendimento que incidem na produtividade se encontram o número de ramas por planta, o número de síliquas por plantas, número de grãos por planta e comprimento da síliquas (COIMBRA et al., 2004; ORTEGÓN-MORALES et al., 2009; KRÜGER et al., 2011; JACOB JUNIOR et al., 2012).

Entre os diversos fatores que afetam o rendimento da canola, a fertilidade do solo tem papel fundamental na produtividade de grãos. A canola é exigente em nitrogênio (N) (NÉMETH et al., 2009; ÖZTÜRK, 2010), inclusive necessitando de maior quantidade de N que a cultura do trigo (HOCKING et al., 1997). Segundo Yasari et al. (2009), o N aumenta a taxa de conversão de carboidratos em proteínas e consequentemente o tamanho das células o que morfologicamente se traduz na expansão da área foliar e maiores taxas de crescimentos.

No entanto, altas doses de $\mathrm{N}$, principalmente na semeadura, podem ser economicamente inviáveis, principalmente pela perda de $\mathrm{N}$ por lixiviação quando há ocorrência de muita chuva, considerando que a eficiência na utilização de $\mathrm{N}$ pela canola é baixa (RATHKE et al., 2006), ou por volatilização do N em épocas de estiagens, por tanto, é importante aplicar o $\mathrm{N}$ de maneira parcelada para melhor aproveitamento do $\mathrm{N}$. Cordeiro et al. (1993) recomendam aplicar $1 / 3$ da dose de $N$ na semeadura e 2/3 da dose em cobertura aos 30 DAS em condições normais de precipitação, e em anos com muita precipitação, aplicar o $\mathrm{N}$ em cobertura aos 60 DAS.

Öztürk (2010) observou que a aplicação de $\mathrm{N}$ incrementou o rendimento de grãos da canola, o teor de óleo e de proteínas em dose de até $100 \mathrm{~kg}$ de $\mathrm{N} \mathrm{ha}^{-1}$. O mesmo autor verificou que a fonte de $\mathrm{N}$ também afeta o rendimento final da canola. Lucas et al. (2013) constataram aumento na produtividade de canola aplicando $180 \mathrm{~kg} \mathrm{de} \mathrm{N} \mathrm{ha}^{-1}$, onde a produtividade de grãos passou de $709 \mathrm{~kg} \mathrm{ha}^{-1}$ a $1132 \mathrm{~kg} \mathrm{ha}^{-1}$. Hocking et al. (1997) constataram que a máxima acumulação de fitomassa ocorreu quando $\mathrm{o} \mathrm{N}$ foi aplicado no inicio da floração, onde a dose de $75 \mathrm{~kg}^{\mathrm{de}} \mathrm{N} \mathrm{ha}^{-1}$ foi a mais eficiente em aumentar o rendimento de grãos.

Por outro lado, existem trabalhos onde a aplicação de $\mathrm{N}$ não produziu aumentos de produtividade de grãos na canola. Rodrigues et al. (2010) estudando três cultivares de colza não constataram diferença significativa na aplicação de diferentes doses de $\mathrm{N}$, pelo que não recomendam aplicar altas doses de N nesta cultura. Diaz e Ortegón (2006) em experimento de três anos na cultura da canola, não constataram resposta da fertilização nitrogenada sobre o rendimento da canola. Sanches et al. (2014) não observaram efeito da aplicação de N na cultura da canola, com e sem irrigação. 
Tagmano et al. (1999) observaram que não houve diferença na aplicação fracionada de $\mathrm{N}$ em diferentes épocas no primeiro ano de experimento. Ao aplicar todo o $\mathrm{N}$ no momento da semeadura obtiveram rendimento de $1.520 \mathrm{~kg} \mathrm{ha}^{-1}$. Quando aplicaram a metade do $\mathrm{N}$ na semeadura e metade no estádio de roseta, obtiveram rendimento de $1.960 \mathrm{~kg} \mathrm{ha}^{-1}$, e quando o fizeram em três aplicações de $\mathrm{N}$, aplicando um terço do $\mathrm{N}$ na semeadura, um terço no fim de roseta e um terço no início da floração o rendimento foi de $2.120 \mathrm{~kg} \mathrm{ha}^{-1}$. No entanto, a aplicação parcelada de $\mathrm{N}$ proporcionou maior rendimento que a testemunha $\left(940 \mathrm{~kg} \mathrm{ha}^{-1}\right)$. No segundo ano de experimento não houve diferença na produção de grãos com e sem aplicação de N.

Para o sul do Brasil, é sugerido aplicar $60 \mathrm{~kg} \mathrm{ha}^{-1}$ de $\mathrm{N}$ na cultura da canola para obter o máximo retorno económico, sendo $15 \mathrm{~kg} \mathrm{ha}^{-1}$ na semeadura e o restante em cobertura, recomendando aplicar o $\mathrm{N}$ no máximo quando a planta apresentar 4 folhas verdadeiras, advertindo que aplicações posteriores a esse estágio não se traduz em maior rendimento de grãos (TOMM et al., 2009).

Considerando que a canola ainda é uma cultura insipiente no Paraguai, não existem muitas pesquisas relacionadas a esta cultura, por tanto, há carência de informações técnicocientíficas relacionadas à adubação, fazendo com que os produtores optem por aplicar baixas doses de fertilizantes, entre eles o $\mathrm{N}$, com receio de terem perdas econômicas com a aplicação de insumos.

O objetivo deste trabalho foi verificar o efeito do manejo da adubação nitrogenada na cultura de canola.

\section{MATERIAL E MÉTODOS}

O experimento foi realizado em Santa Rita, Alto Paraná, Paraguai, nas coordenadas geográficas UTM 21J 692.387 m E e 7.148.245 m S, a 304 m de altitude média, em condições de campo. Os dados meteorológicos da precipitação pluvial diária durante a condução do experimento são apresentados na Figura 1.

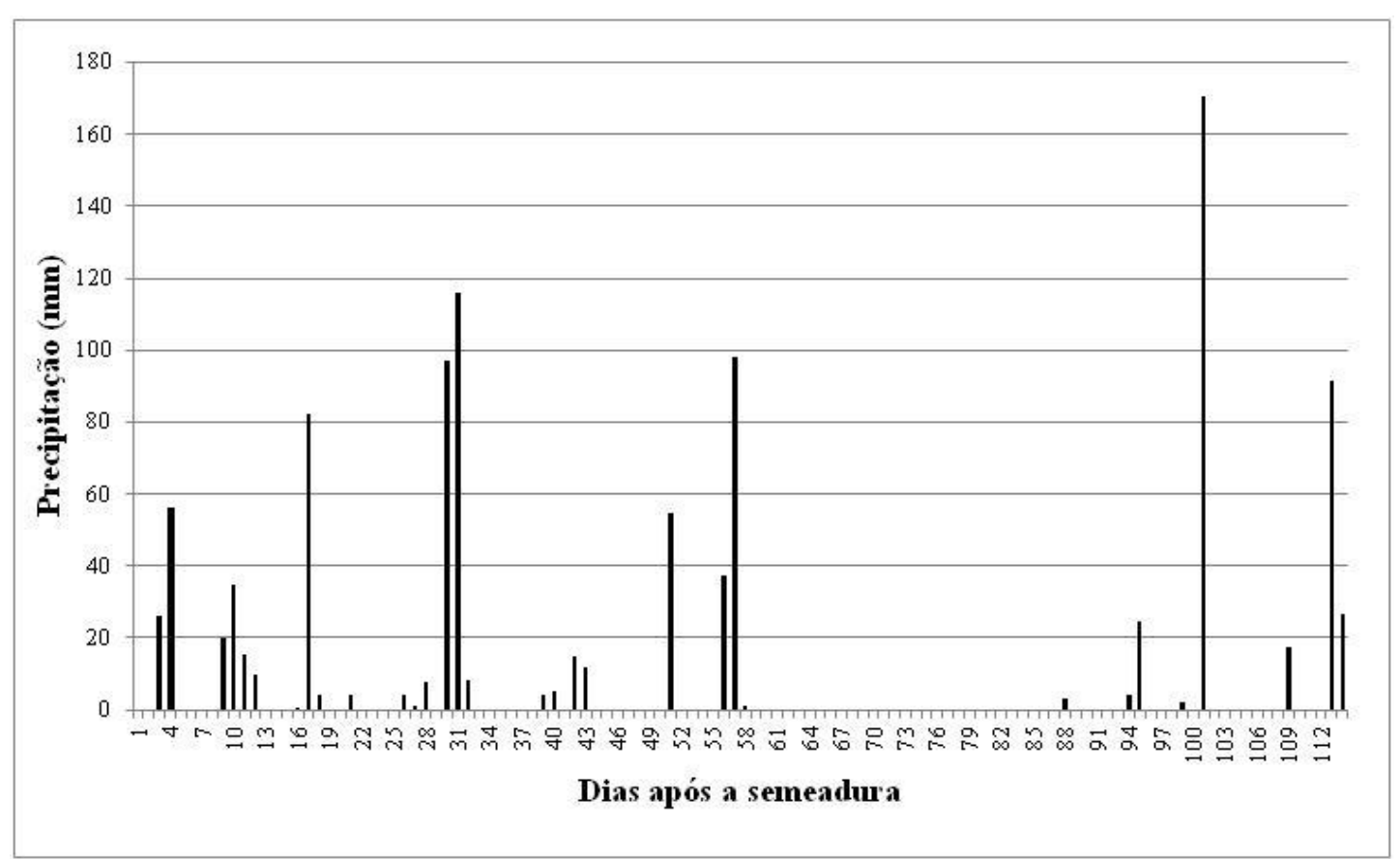

Figura 1. Precipitações diárias ocorridas durante o ciclo da cultura da canola, desde a semeadura até a colheita, no presente experimento. Santa Rita, Alto Paraná, 2014 
O solo onde foi realizado o experimento é classificado como Rhodic Paleudalf (LÓPEZ et al., 1995). Inicialmente foram coletadas amostra de solo na profundidade de 0,0 $0,10 \mathrm{~m}$, para análise química (Tabela 1 ).

Tabela 1. Resultado de análise química e física do solo $(0,00-0,10 \mathrm{~m})$, antes da implantação do experimento. Santa Rita, Alto Paraná, 2014

\begin{tabular}{|c|c|c|c|c|c|c|c|c|c|c|}
\hline $\begin{array}{c}\mathrm{pH} \\
\left(\mathrm{H}_{2} \mathrm{O}\right)\end{array}$ & $\begin{array}{c}\mathrm{MO} \\
\mathrm{g} \mathrm{dm}^{-3}\end{array}$ & $\begin{array}{lr}\mathrm{P} & \mathrm{S} \\
\mathrm{mg} \mathrm{dm} & \end{array}$ & & & $\begin{array}{l}\mathrm{Ca}^{+2} \mathrm{Mg}^{+2} \\
. . \mathrm{cmol}_{\mathrm{c}} \mathrm{kg}^{-1} \ldots\end{array}$ & $\mathrm{K}^{+}$ & CTC & $\begin{array}{c}\text { Areia } \\
\ldots \ldots . .\end{array}$ & & \\
\hline 5,5 & 32,8 & $\begin{array}{ll}50,1 & 128\end{array}$ & 21 & 0,00 & 6,76 & ט & 10,1 & 24,1 & 33,8 & \\
\hline
\end{tabular}

Adotou-se o delineamento experimental de blocos ao acaso, com cinco tratamentos e quatro repetições, que consistiram em diferentes doses e épocas de aplicação de $\mathrm{N}$ na cultura da canola (Tabela 2). Cada parcela foi constituída por 8 linhas de $5 \mathrm{~m}$ de comprimento, com espaçamento de $0,45 \mathrm{~m}$ entre linhas, num total de $18 \mathrm{~m}^{2}(5 \mathrm{~m} \times 3,6 \mathrm{~m})$ por unidade experimental.

Tabela 2. Época e dose de $\mathrm{N}$ aplicado nos diferentes tratamentos, na cultura da canola. Santa Rita, Alto Paraná, 2014

\begin{tabular}{ccccc}
\hline Tratamentos & $\begin{array}{c}\text { Dose de N na } \\
\text { semeadura }\end{array}$ & $\begin{array}{c}\text { Dose de N aos } \\
\text { 25 DAS, no } \\
\text { estádio B4, } \\
\text { (inicio de roseta) }\end{array}$ & $\begin{array}{c}\text { Dose de N aos } \\
\text { 35 DAS, no } \\
\text { estádio B6, } \\
\text { (Roseta) }\end{array}$ & $\begin{array}{c}\text { Dose de N aos } \\
50 \text { DAS, no } \\
\text { estádio E, } \\
\text { (Floração) }\end{array}$ \\
\hline T1 & 0 & 0 & 0 & 0 \\
T2 & 15 & 0 & 0 & 0 \\
T3 & 15 & 46 & 0 & 0 \\
T4 & 15 & 0 & 46 & 0 \\
T5 & 15 & 23 & 0 & 23 \\
\hline
\end{tabular}

DAS = Dias após a semeadura

O solo da área do experimento vem sendo utilizado no sistema plantio direto a mais de 10 anos. O solo antes de implantar o experimento de canola estava cultivado por soja.

As doses de $\mathrm{N}$ na semeadura foram aplicadas manualmente, por ocasião da semeadura, na forma de ureia. $\mathrm{O} \mathrm{N}$ em cobertura foi aplicado na forma de ureia, a lanço e sem incorporação, após a chuva. Utilizou-se semeadora/adubadora para aplicação de $100 \mathrm{~kg} \mathrm{ha}{ }^{-1}$ de $0-15-15$ N- $\mathrm{P}_{2} \mathrm{O}_{5}-\mathrm{K}_{2} \mathrm{O}$. A dose de potássio e fósforo aplicado foi baixa porque o solo apresentava teores muito alto de ambos nutrientes (BRITOS et al., 2012; MORENO et al., 2012). Foi semeada entre 18 a 20 sementes por metro, com estandes de 40-45 plantas por metro quadrado.

O experimento foi implantado no dia 28 de maio e colhido no dia 20 de setembro de 2014. A canola foi instalada em sucessão á cultura da soja. Utilizou-se o híbrido Hyola 61 que apresenta resistência poligênica ao fungo causador da canela-preta, ciclo médio de 123 a 155 dias, altura média de plantas de 78 a $129 \mathrm{~cm}$ e excelente desempenho sob deficiência hídrica e frio intenso (TOMM et al., 2009).

Foi avaliada a altura de planta aos 60 dias após a semeadura e no momento da colheita, o número de síliquas, a produtividade de grãos da canola e a massa de mil grãos. A coleta das informações foi realizada dentro da área útil de cada unidade experimental.

A altura de planta aos 60 dias da semeadura e no final do período reprodutivo foi obtida da altura do dossel em 10 pontos, tendo-se medido da base até a extremidade superior 
dos ramos; o número de síliquas por planta foi obtido a partir da contagem de 10 plantas por unidade experimental; a produtividade de grãos foi obtida da debulhada de todas as plantas da área útil, com posterior secagem dos grãos em estufa a $65{ }^{\circ} \mathrm{C}$ até estas atingirem massa constante.

Os dados do experimento foram submetidos à análise de variância e, quando significativos pelo ANOVA, aplicado o teste de Tukey ao 5\% e 1\% de probabilidade.

Os dados relativos às variáveis medidas tendo-se utilizando o programa ASISTAT (SILVA, 2014).

Foi determinado o coeficiente de correlação de Pearson entre as variáveis avaliadas, considerando a média de cada unidade experimental, aplicando a fórmula:

Onde: $C o v=$ covarianza, $X$ e $Y=$ média das amostras de cada matriz, neste caso a unidade experimental y $\sigma=$ desvio padrão de cada matriz. Quando $r$ é maior a 0,7 há forte correlação, $r$ entre 0,7 a 0,3 indica correlação moderada e $r$ menor a 0,3 indica baixa correlação, considerando o teste de t ao nível de 5 y $1 \%$.

\section{RESULTADOS E DISCUSSÃO}

A aplicação de $\mathrm{N}$ produziu efeito em todas as variáveis analisadas, com exceção da massa de mil grãos (Tabela 3).

Tabela 3. Valores de F e coeficiente de variação para altura de planta aos 60 dias após a semeadura (DAS), altura final de planta, número de síliquas por planta, rendimento e massa de 1000 grãos. Santa Rita, Alto Paraná, 2014

\begin{tabular}{lccccc}
\hline & $\begin{array}{c}\text { Altura de } \\
\text { planta aos } \\
\text { 60 DAS }\end{array}$ & $\begin{array}{c}\text { Altura final } \\
\text { de planta }\end{array}$ & $\begin{array}{c}\text { Síliquas por } \\
\text { planta }\end{array}$ & Rendimento & $\begin{array}{c}\text { Massa de 1.000 } \\
\text { grãos }\end{array}$ \\
\hline Valor F & $47,5^{* *}$ & $89,3^{* *}$ & $137,4^{* *}$ & $2654^{* *}$ & $0,13^{\text {ns }}$ \\
CV $(\%)$ & 6,04 & 2,20 & 6,64 & 1,51 & 1,80 \\
\hline ns: Não significativo; ** Significativo a p $\leq 0,01$ pelo teste de Tukey; CV: Coeficiente de variação &
\end{tabular}

A altura de planta aos 60 DAS aumentou com a aplicação de N, sendo maior a altura nos tratamentos que receberam adubação nitrogenada na semeadura e cobertura, quando comparada só a aplicação de N na base (Tabela 4).

Era de esperar-se diferença entre os tratamentos T3, T4 e T5 aos 60 DAS, devido ao tempo que passou entre a aplicação de $\mathrm{N}$ em cobertura e a medição da altura, que foram de 35 dias, 25 dias e 35, respectivamente, no entanto não houve diferença de altura entre estes tratamentos (Tabela 4). A aplicação somente de $\mathrm{N}$ na base, como é realizada comumente pelos produtores da região (T2), produz plantas de 60 dias com menor altura que quando aplicado $\mathrm{N}$ suplementar em cobertura, mas a aplicação de $15 \mathrm{Kg}_{\text {de }} \mathrm{N}^{-1}{ }^{-1}$ (T2) é suficiente para aumentar a altura de planta quando comparado com a testemunha (T1), mesmo em uma lavoura de canola após a cultura da soja, pois a rápida decomposição da palhada das leguminosas libera nitrogênio para a cultura seguinte. Sanches et al. (2014), não encontraram diferença na altura de planta aos 67 DAS por efeito da fertilização nitrogenada.

A altura final de planta apresentou comportamento similar à altura de planta aos 60 DAS (Tabela 4), apresentando a menor altura o tratamento testemunha (T1), seguido pelo tratamento com $15 \mathrm{~kg}$ de $\mathrm{N} \mathrm{ha}^{-1}$ na semeadura (T2), e comportamento similar entre os 
tratamentos que receberam $\mathrm{N}$ em cobertura (T3, T4 e T5), sem importar a época de aplicação do N, quando realizado em cobertura. Diaz e Ortegón (2006) e Sanches et al. (2014), não constataram diferença na altura final de planta por efeito da fertilização nitrogenada.

Tabela 4. Altura de planta de canola aos 60 dias após a semeadura (DAS), e a altura final de planta por efeito do manejo da adubação nitrogenada. Santa Rita, Alto Paraná, 2014

\begin{tabular}{|c|c|c|}
\hline $\begin{array}{l}\text { Tratamentos } \\
\mathrm{kg} \text { de } \mathrm{N} \mathrm{ha}^{-1}\end{array}$ & $\begin{array}{c}\text { Altura de } \\
\text { planta aos } 60 \\
\text { DAS }\end{array}$ & $\begin{array}{l}\text { Altura final } \\
\text { de planta }\end{array}$ \\
\hline T1: 0 & $25,6 \mathrm{c} * *$ & $92,1 \mathrm{c}^{* *}$ \\
\hline T2: 15 na semeadura & $32,9 \mathrm{~b}$ & $105,9 \mathrm{~b}$ \\
\hline T3: 15 na semeadura, 46 no inicio da roseta (B4). & $44,9 \mathrm{a}$ & $115,3 \mathrm{a}$ \\
\hline T4: 15 na semeadura, 46 na roseta (B6). & $40,7 \mathrm{a}$ & $117,3 \mathrm{a}$ \\
\hline $\begin{array}{l}\text { T5: } 15 \text { na semeadura, } 23 \text { no inicio de roseta }(B 4) \text { e } 23 \mathrm{~N} \text { na } \\
\text { floração }(\mathrm{E}) \text {. }\end{array}$ & $40,5 \mathrm{a}$ & $120,3 \mathrm{a}$ \\
\hline
\end{tabular}

Fica evidente que a aplicação de apenas $15 \mathrm{~kg}$ de $\mathrm{N} \mathrm{ha}^{-1}$ na cultura da canola, quando semeada em sucessão à cultura da soja (T2), como é comumente realizado pela maioria dos produtores da região não é suficiente para suprir a quantidade de $\mathrm{N}$ que a cultura da canola necessita para o bom crescimento avaliado pela altura de planta, pois a aplicação de dose superior a $15 \mathrm{~kg} \mathrm{ha}^{-1}$ permitiu aumenta na altura de planta aos 60 DAS y na altura final de planta.

Öztürk (2010) obteve maior altura de planta, com a aplicação de $\mathrm{N}$ a metade na semeadura e a metade no inicio da floração, sendo a melhor dose que permitiu a maior altura $(131 \mathrm{~cm})$ a de $150 \mathrm{~kg}$ de $\mathrm{N}^{-}{ }^{-1}$. Segundo Kaefer et al. (2014) a aplicação de $\mathrm{N}$ têm influencia na altura final de planta, onde o maior crescimento da canola se deu com a aplicação de 80 e $82 \mathrm{~kg}$ de $\mathrm{N} \mathrm{ha}^{-1}$ nos anos 2009 e 2010, respectivamente, com altura de planta de 91 e $116 \mathrm{~cm}$ para esses anos agrícolas, respectivamente. Afridi et al. (2002) constataram que a aplicação de $100 \mathrm{~kg}$ de $\mathrm{N} \mathrm{ha}^{-1}$ somente na semeadura produz plantas mais altas que a aplicação parcelada de $\mathrm{N}$, metade na semeadura e metade na floração.

A aplicação de $\mathrm{N}$ na semeadura permitiu aumento no número de síliquas na cultura da canola, quando comparado com o tratamento que não recebeu $\mathrm{N}$ (Tabela 5).

Os tratamentos que receberam aplicação de $\mathrm{N}$ em cobertura (T3, T4 e T5) apresentaram maior número de síliquas que os tratamentos que não receberam (T1 e T2), ao contrario do que aconteceu com a altura de planta, a época de aplicação de $\mathrm{N}$ em cobertura afetou o número de síliquas, sendo que a aplicação de $\mathrm{N}$ em cobertura, realizada em duas ocasiões (T5) parceladamente permitiu a formação de maior número de síliquas por planta que quando aplicado em uma só vez (T3 e T4).

Mesmo quando aplicado o $\mathrm{N}$ em cobertura em uma só ocasião, é importante a época de aplicação (Tabela 5), pois a aplicação quando a planta se encontra em estádio de roseta (B6) produziu maior número de síliquas (210 síliquas por planta) que quando o $\mathrm{N}$ em cobertura foi aplicado no inicio de formação de rozeta (B4 -182 síliquas por planta). A aplicação de $\mathrm{N}$ em cobertura, e principalmente em forma parcelada (T5), permitiu maior número de ramificações laterais, consequentemente maior número de síliquas por plantas. 
Tabela 5. Número de síliquas por planta, rendimento da canola e massa de 1000 grãos por efeito do manejo da adubação nitrogenada. Santa Rita, Alto Paraná, 2014

\begin{tabular}{|c|c|c|c|}
\hline $\begin{array}{l}\text { Tratamentos } \\
\text { kg de } \mathrm{N} \mathrm{ha}^{-1}\end{array}$ & $\begin{array}{l}\text { Síliquas } \\
\text { por planta }\end{array}$ & $\begin{array}{l}\text { Rendimento } \\
\ldots . \mathrm{kg} \mathrm{ha}^{-1} \ldots\end{array}$ & $\begin{array}{l}\text { Massa de } \\
\text { mil grãos } \\
\ldots . . . . \mathrm{g} \text {....... }\end{array}$ \\
\hline T1: 0 & $86 \mathrm{e}^{* * *}$ & $607 \mathrm{e}^{* *}$ & $4,20^{\mathrm{ns}}$ \\
\hline T2: 15 na semeadura & $124 \mathrm{~d}$ & $896 \mathrm{~d}$ & 4,22 \\
\hline T3: 15 na semeadura, 46 no inicio da roseta (B4). & $182 \mathrm{c}$ & $1362 \mathrm{c}$ & 4,20 \\
\hline T4: 15 na semeadura, 46 na roseta (B6). & $210 \mathrm{~b}$ & $1478 \mathrm{~b}$ & 4,22 \\
\hline $\begin{array}{l}\text { T5: } 15 \text { na semeadura, } 23 \text { no inicio de roseta (B4) } \\
\text { e } 23 \text { N na floração }(E) \text {. }\end{array}$ & $252 \mathrm{a}$ & $1808 \mathrm{a}$ & 4,20 \\
\hline
\end{tabular}

Letras diferentes são estatisticamente diferentes, de acordo ao teste de Tukey $\mathrm{P}<0,01$; ns: não significativo.

Kaefer et al. (2014) constataram que a aplicação de $\mathrm{N}$ aumenta a produção de massa seca de síliquas, A aplicação de $\mathrm{N}$ em dose de 83 e $98 \mathrm{~kg} \mathrm{ha}^{-1}$, foram as doses que proporcionaram maior massa de síliquas por planta (43 g e 23 g) em 2009 e 2010, respectivamente. Öztürk (2010) obteve maior número de síliquas por planta (entre 263 a 283 síliquas) aplicando entre 50 a $150 \mathrm{~kg}$ de $\mathrm{N} \mathrm{ha}^{-1}$.

Com base nos resultados obtidos pode-se afirmar que aplicações parceladas de $\mathrm{N}$, em época adequada aumenta o número de síliquas por planta, e consequentemente o rendimento de grãos, resultados diferentes obtidos por Tomm et al. (2009) que sugerem a aplicação de N em cobertura no máximo quando a planta possui 4 folhas verdadeiras.

Cordeiro et al. (1993) afirmam que a deficiência de $\mathrm{N}$ causa retraso na floração, e desuniformidade na formação de síliquas o que finalmente afeta o momento da colheita de grãos, pela desuniformidade da maturação.

Estes resultados coincidem com os de Tamango et al. (1999) que sustentam que a aplicação de dose apropriada de $\mathrm{N}$ podem aumentar o rendimento de grãos, já que este nutriente na presença de condições ambientais adequadas melhora o índice de área foliar, a fitomassa total de planta, número de flores por planta, promovem o aumento do número de síliquas por unidade de superfície, produzindo maior quantidade de grãos e consequentemente maior rendimento.

Leterme (1988) afirmam que tanto o número de síliquas por plantas, como o número de sementes por sílicua dependem da nutrição carbonatada proveniente da atividade fotossintética das folhas, onde o $\mathrm{N}$ é o principal nutriente que colabora para o crescimento e dessenvolvimento foliar. Cheema et al. (2001) afirmam que o fornecimento adequado de $\mathrm{N}$ não só incrementa o crescimento e desenvolvimento, mas também colabora com a manutenção de folhas fotosintéticamente ativas, melhorando também a produção de flores e síliquas.

A aplicação de $15 \mathrm{~kg} \mathrm{de} \mathrm{N} \mathrm{ha}^{-1}$ na semeadura permitiu aumento no rendimento de grãos (T2), quando comparado com a testemunha (T1) na cultura da canola. Assim como a aplicação de $\mathrm{N}$ em cobertura (T3, T4, e T5), quando comparado com o rendimento do tratamento sem aplicação de $\mathrm{N}$ em cobertura (Tabela 5).

Em relação aos tratamentos com aplicação de $\mathrm{N}$ em cobertura, se observa que o parcelamento do $\mathrm{N}$ teve efeito significativo no rendimento de grãos. $\mathrm{O}$ tratamento onde foi

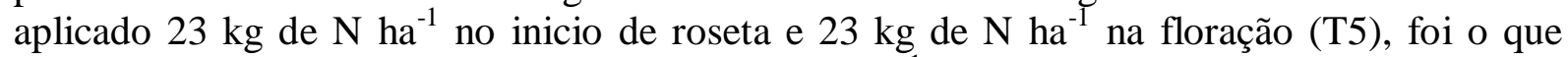
apresentou maior rendimento de grãos $\left(1.808 \mathrm{~kg} \mathrm{ha}^{-1}\right)$, sendo superior aos tratamentos que receberam o $\mathrm{N}$ em cobertura apenas em uma aplicação. Entre estes, a aplicação de $\mathrm{N}$ no momento da floração permitiu maior rendimento de grãos $\left(1.478 \mathrm{~kg} \mathrm{ha}^{-1}\right)$ que quando 
aplicado o $\mathrm{N}$ no início da floração $\left(1.362 \mathrm{~kg} \mathrm{ha}^{-1}\right)$. Os resultados de rendimento deste trabalho se contradizem com o recomendado por Tomm et al. (2009) que sugere aplicar o $\mathrm{N}$ em cobertura no máximo quando a planta possui 4 folhas verdadeiras.

Estes resultados confirmam que o $\mathrm{N}$ é um nutriente limitante na cultura da canola, na região de estudo, já que todos os tratamentos que receberam fertilização nitrogenada apresentaram maiores rendimentos que a testemunha, concordando com os trabalhos de Hocking et al. (1997); Németh et al. (2009); Öztürk, (2010); Lucas et al. (2013) e Kaefer et al. (2014).

Hocking et al. (1997) afirmam que a fase mais importante no abastecimento de $\mathrm{N}$ para produção de fitomassa seca, é o período entre o início e o fim da floração, onde a maior absorção de $\mathrm{N}$ começa antes da floração, e $\mathrm{N}$ utilizado no crescimento e desenvolvimento de grãos é aquele que provém do $\mathrm{N}$ mobilizado principalmente a partir do caule e folhas. Barlóg e Grzebisz (2004) afirmam que o rendimento de grãos depende principalmente do N acumulado nas folhas no fim da floração, e que a acumulação de $\mathrm{N}$ na haste principal da canola, no início da maturidade é responsável em $69 \%$ do rendimento final de grãos.

Afridi et al. (2002) observaram resposta da canola a aplicação de $100 \mathrm{~kg}$ de $\mathrm{N} \mathrm{ha}^{-1}$, no entanto, não observaram diferença na produtividade de grãos com aplicação em dose única ou parcelada de $\mathrm{N}$, metade na semeadura e metade na floração.

O ano de 2014 foi atípico na região do experimento, pois houve muita precipitação, principalmente nos primeiros 60 dias de implantado a cultura da canola (Figura 1). Considerando que a precipitação foi superior que a média do lugar, a aplicação precoce de $\mathrm{N}$, como no caso do T3, onde foi aplicado o $\mathrm{N}$ no inicio do florescimento, aos 25 DAS e no T4, em pleno florescimento, aos 35 DAS, possivelmente facilitou a lixiviação deste elemento, sendo afetada sua disponibilidade, pois houve abundante precipitação até os 60 DAS (Figura 1). Enquanto mais fracionada foi à aplicação de $\mathrm{N}$ maior foi a produtividade, no entanto, a aplicação do $\mathrm{N}$ em mais de uma vez em cobertura pode ser inviável do ponto de vista económico, considerando o custo de aplicação de $\mathrm{N}$.

A precipitação registrada durante o desenvolvimento da cultura entre maio e outubro foi de $1050 \mathrm{~mm}$, sendo superior a quantidade de agua que é exigida pela canola, que é de 210 e $350 \mathrm{~mm}$ para a etapa vegetativa e reprodutiva, respectivamente, segundo Inzunza-Ibarra et al. (2014), além disso, a temperatura média foi de $19,5{ }^{\circ} \mathrm{C}$ influenciando de forma positiva o bom crescimento da canola, embora a estiagem ocorrida em agosto pode ter afetado o rendimento final de grãos, considerando que a canola é susceptível a deficiência d'água, e sendo o rendimento afetado pelo déficit hídrico (BILIBIO et al., 2011), pois na região o rendimento da canola em 2013 foi de $1201 \mathrm{~kg} \mathrm{ha}^{-1}$ (CAPECO, 2013)

Os resultados obtidos de massa de 1000 grãos foram similares entre tratamentos, oscilando entre 4,20 g e 4,22 g (Tabela 5). Öztürk (2010) obteve aumento de massa de 1000 grãos, alcançando 4,3 g com o fornecimento de $150 \mathrm{~kg}$ de $\mathrm{N} \mathrm{ha}^{-1}$. Hocking et al. (1997) alegam que o aumento do rendimento de canola pela aplicação de $\mathrm{N}$ se deve ao aumento do número de síliquas e não pelo aumento de massa de grãos. Villar (1999) afirma que as diferenças entre a massa de 1000 grãos variam principalmente entre cultivares antes que pelo ambiente.

No entanto, Kaefer et al. (2014) observaram aumento da massa de 1000 grãos com a aplicação de N, onde os autores registraram massa de 2,8 e 3,0 g pela aplicação de 79 e $72 \mathrm{~kg}$ de $\mathrm{N} \mathrm{ha}^{-1}$ para os anos 2009 e 2010, respectivamente. Sendo os valores encontrado por Kaefer et al. (2014) inferiores aos encontrados no presente experimento. 
Existe correlação forte, positiva e altamente significativa entre a altura de planta aos 60 DAS e a altura final de planta $(r=0,85)$; entre a altura de planta aos 60 DDS e o número de síliquas $(r=0,78)$ y entre a altura de planta aos 60 DDS e o rendimento $(r=0,82)$, no entanto, não existe correlação entre altura de plantas aos 60 DDS e massa de 1.000 grãos $(\mathrm{r}=$ 0,17) (Tabela 6). Isto demonstra que, em condições normais, a altura de planta, ou seu estado de crescimento, pode ser um bom indicativo sobre a possibilidade de produtividade da canola.

Tabela 6. Coeficientes de correlação fenotípica de Pearson entre as variáveis analisadas na cultura da canola. Santa Rita, Alto Paraná, 2014

\begin{tabular}{llllll}
\hline Caracteres & APS & AFP & NSP & RG & MG \\
\hline APS & 1,00 & $0,85^{* *}$ & $0,78^{* *}$ & $0,82^{* *}$ & $0,17^{\text {ns }}$ \\
AFP & & 1,00 & $0,92^{* *}$ & $0,94 * *$ & $0,07^{\text {ns }}$ \\
NSP & & 1,00 & $0,99 * *$ & $0,14^{\text {ns }}$ \\
RG & & & 1,00 & $0,16^{\text {ns }}$ \\
MG & & & & & 1,00 \\
\hline
\end{tabular}

APS = altura de planta aos 60 días; AFP = altura final de planta; $\mathrm{NSP}=$ número de síliquas por planta; $\mathrm{RG}=$ rendimento de grãos; $\mathrm{MG}=$ massa de grãos. ${ }^{* *}$ Significativo $\mathrm{t}<0,01 ;{ }^{\mathrm{ns}}=$ não significativo.

Foi observada correlação forte, positiva e altamente significativa entre a altura final de planta e o número de síliquas $(\mathrm{r}=0,92)$ e entre a altura final de planta e o rendimento $(\mathrm{r}=$ 0,94). Isto demostra que plantas maiores possivelmente terão maior quantidade de síliquas e consequentemente maior rendimento. No entanto, Coimbra et al. (2004) afirmam que não existe associação entre a altura de planta e o rendimento de grãos de canola. Assim como a altura de planta aos $60 \mathrm{DAS}$, não houve correlação entre a altura final de planta e a massa de 1000 grãos $(r=0,07)$, concordando com os dados encontrados com Coimbra et al. (2004), quem tiveram resultados similares.

Existe correlação forte, positiva e altamente significativa entre o número de síliquas e o rendimento $(r=0,99)$, no entanto, não existe correlação entre o número de síliquas e a massa de 1000 grãos $(r=0,14)$. Plantas com maior número de síliquas apresentam maior rendimento de grãos, pois maior número de síliquas representa maior número de grãos por superfície, consequentemente maior rendimento.

Ortegón-Morales et al. (2009) constataram forte correlação entre o número de síliquas e o rendimento de grãos. Coimbra et al. (2004) também constataram que o número de síliquas por planta possui correlação positiva com o rendimento da canola. Hocking et al. (1997) alertava que a fertilização nitrogenada incrementa o rendimento através do incremento de síliquas por planta, sendo este fator mais importante que o número de sementes por síliquas ou massa de sementes em si. Jacob Junior et al. (2012) observaram que o número de síliquas por planta foi o componente do rendimento que mais influenciou no rendimento de planta.

Não existe correlação entre o rendimento e a massa de 1000 grãos $(r=0,16)$ devido a que a massa de grãos depende mais das características do cultivar que do meio onde o mesmo se desenvolve (VILLAR, 1999). Hocking et al. (1997) constataram que a aplicação de N incrementou a quantidade de síliquas, no entanto, não aumentou o peso de mil grãos.

\section{CONCLUSÕES}

A aplicação de $\mathrm{N}$ aumentou o rendimento de grãos de canola, propiciando maior rendimento quando aplicado $\mathrm{N}$ na base e em cobertura em forma parcelada, no inicio da roseta e na floração. 


\section{REFERÊNCIAS BIBLIOGRÁFICAS}

AFRIDI, M. Z.; JAN, M. T.; SHAD, A. A. Some aspects of NPK nutrition for improved yield and oil contents of canola. Asian Journal Plant Science, Faisalabab, v. 1, n. 1, p. 507509, 2002.

BARLÓG, P.; GRZEBISZ, W. Effect of timing and nitrogen fertilizer application on winter oilseed rape (Brassica napus L.). II. Nitrogen uptake dynamics and fertilizer efficiency. Journal Agronomy and Crop Science, Saskatoon, v. 190, n. 1, p. 314-323. 2004.

BILIBIO, C.; CARVALHO, J. A.; HENSEL, O.; RICHTER, U. Effect of different levels of water déficit on rapeseed (Brassica napus L.). Ciências Agrotécnicas, Lavras-MG, v. 35, n. 4, p. 672-684, 2011.

BRITOS-BENITTEZ, C. A.; CAUSARANO-MEDINA, H. J.; RASCHE-ALVAREZ, J. W.; BARRETO-RIQUELME, U. F.; MENDOZA-DUARTE, F. Fertilización fosfatada de los principales cultivos bajo siembra directa mecanizada en la región Oriental del Paraguay. Investigación Agraria, San Lorenzo, v. 14 n: 2, p. 87-92, 2012.

CHEEMA, M. A.; MALIK, M.A.; HUSSAIN, A.; SHAH, S.H.; BASRA, S.M.A. Effects of time and rate of nitrogen and phosphorus application on the growth and seed and oil yields of canola (Brassica napus L.). Journal of Agronomy and Crop Science, Saskatoon, v. 186, n. 2, p. 103-110, 2001.

CHEEMA, M. A.; SALEEM, M. F.; MUHAMMAD, N.; WAHID, M. A.; BABER, B. H. Impact of rate and timing of nitrogen application on yield and quality of canola (Brassica napus L.). Pakistan Journal of Botany, Karachi, v. 42, n. 1, p. 1723- 1731, 2010.

COIMBRA, J. L. M.; GUIDOLLIN, A. F; ALMENIDA, M. L.; SANGOI, L.; ENDER, M.; MEROTTO JÚNIOR, A. Análise de trilha dos componentes do rendimento de grãos em genótipos de canola. Ciência Rural, Santa Maria-RS, v. 34, n. 5, p. 1421- 1428, 2004.

CORDEIRO, D. S.; SILVEIRA, E. P.; KECHEL, A. N. Resposta da Brassica napus a doses e épocas de aplicação de nitrogênio. Pesquisa Agropecuária Brasileira, Brasília-DF, v. 28, n. 10, p.1137-1142, 1993.

DALMAGO, G. A.; FOCHESATTO, E.; KOVALESKI, S.; TAZZO, I. F.; BOLIS, L. M.; CUNHA, G. R.; NIED, A. H.; BERGAMASCHI, H.; SANTI, A. Filocrono e número de folhas da canola em diferentes condições ambientais Pesquisa Agropecuária Brasileira, Brasília-DF, v. 48, n. 6, p. 573-581, 2013.

DIAZ, F. A.; ORTEGÓN, M. A. S. Efecto de inoculación con Azospirillum brasiliense y fertilización química en el crecimiento y rendimeirnto de canola (Brassica napus). Revista Fitotécnica Mexicana, México, v. 29, n. 1, p. 63-67, 2006.

HOCKING, P. J.; RANDALL, P. J.; De MARCO, D.; BAMFORTH, I. Assessment of the nitrogen status of field-grown canola (Brassica napus) by plant analysis. Australian Journal of Experimental Agriculture, Clayton South, v. 37, n. 1, p. 83-92, 1997.

INBIO (Instituto de Biotecnología Agrícola). 2013. Estimación de superficie de cultivos de invierno. Cubilla R, L.E; Pekholtz, F. (Organizadores). Disponible en: http://www.inbio.org.py/biblioteca/estimacion de superficies.

INZUNZA-IBARRA, M. A; CATALÁN-VALENCIA, E. A.; VILLA-CASTORENA, M. M.; SÁNCHEZ-COHEN, I.; SIFUENTES-IBARRA, E.; ROMÁN-LÓPEZ, A. Modelos de predicción de rendimiento de canola en función del contenido de humedad disponible en el suelo. Revista Fitotecnia Mexicana, México. v. 37, n.1, p. 49-58, 2014. 
JACOB JUNIOR, E.A.; MERTZ, L. M.; HENNING, F. A.; QUILÓN, I. R.; MAIA, M. S.; ALTISENT, J.M.D. Changes in canola plant architecture and seed physiological quality in response to different sowing densities. Revista Brasileira de Sementes, Londrina-PR, v. 34, n.1, p.14-20, 2012.

KAEFER, J. E.; GUIMARÃES, V. F.; RICHART, A.; TOMM, G. O.; MÜLLER, A. L. Produtividade de grãos e componentes de produção da canola de acordo com fontes e doses de nitrogênio. Pesquisa Agropecuária Brasileira, Brasília-DF, v. 49, n. 4, p. 273-280, 2014.

KRÜGER, C. A. M. B.; SILVA, J. A. G; MEDEIROS, S. L. P.; DALMAGO, G. A.; GAVIRAGHI, J. Herdabilidade e correlação fenotípica de caracteres relacionados à produtividade de grãos e à morfologia da canola. Pesquisa Agropecuária Brasileira, Brasília-DF, v. 46, n. 12, p. 1625-1632, 2011.

LETERME, P. H. Croissance et développement du colza d'hiver: Les principales étapes. En Physiologie et èlaboration $d u$ rendement $d u$ colza d'hiver. Centre Technique Interprofessionel des Oleagineaux Metropolitains (CETIOM), p. 23-33,1988.

LÓPEZ, O.; GONZALEZ, E; LLAMAS, P. A; MOLINAS, A. S; FRANCO, E. S.; GARCÍA, S.; RÍOS, E. O. Mapa de Reconocimiento de Suelos de la Región Oriental. Paraguay, Banco Mundial. DMA.Esc.1500.000. 1995.

LUCAS, F. T.; COUTINHO, E. L. M.; PAES, J. M. V.; BARBOSA, J. C. Produtividade e qualidade de grãos de canola em função da adubação nitrogenada e sulfatada. Semina: Ciências Agrárias, Londrina-PR, v. 34, n. 6, p. 3205-3218, 2013.

NÉMETH , T., MÁTHÉ-GÁSPÁR, G.; RADIMSZKY, L.; GYO’RI, Z. Nitrogen and Sulfur Content of Canola Grown on a Calcareous Chernozem Soil, Communications in Soil Science and Plant Analysis, Londres, v. 40, n. 1, p. 1-6, 825-834, 2009. DOI: 10.1080/00103620802695040.

MORENO-RESQUIN, H.; CAUSARANO-MEDINA, H. J.; RASCHE-ALVAREZA, J. W.; BARRETO-RIQUELME, U.; MENDOZA-DUARTE, F. Fertilización potásica de los principales cultivos bajo siembra directa mecanizada en la región Oriental del Paraguay. Investigación Agraria, San Lorenzo, v. 14 n. 1, p. 87-92, 2012.

ORTEGÓN-MORALES， A. S.; GONZÁLEZ-QUINTERO, J.; DÍAZ-FRANCO, A.; CASTILLO-TORRES, N. Componentes de rendimiento de canola (Brassica napus 1.) en siembra a baja densidad de población. Universidad y Ciencias; Trópico Húmedo, Villahermosa, v. 25, n. 3, p. 267-272, 2009.

ÖZTÜRK, Ö. Effects of source and rate of nitrogen fertilizer on yield, yield components and quality of winter rapeseed (Brassica napus L.). Chilean Journal of Agricultural Research, Chillán, v. 70, p. 132-141, 2010.

RATHKE , G. W.; BEHRENS, B.; DIEPENBROCK, W. Integrated nitrogen management strategies to improve seed yield, oil content and nitrogen efficiency of winter oilseed rape (Brassica napus L.): a review. Agriculture, Ecosystems and Environment, Holland, v. 117, n. 1, p.80-108, 2006.

RATHKE, G. W.; CHRISTEN, O.; DIEPENBROCK, W. Effects of nitrogen source and rate on productivity and quality of winter oilseed rape (Brassica napus L.) grown in different crop rotations. Field Crops Research, Holland, v. 94, n. 1. p. 103-113, 2005.

RODRIGUES, M. A.; FERREIRA, I.; ARROBAS, M. Ensaios com cultivares de colza de inverno, doses de azoto e profundidades de sementeira em Trás-os-Montes. Revista de Ciências Agrárias, Lisboa, v. 33, n. 2, p. 27-39, 2010. 
SANCHES, A. C.; GOMES, E. P.; RAMOS, W. B.; MAUAD, M.; DOS SANTOS, S.; BISCARO, G. G. Produtividade da canola sob irrigação e doses de adubação nitrogenada. Revista Brasileira de Engenharia Agrícola e Ambiental, Campina Grande-PB, v. 18, n. 7, p. 688-693, 2014.

SILVA, F. A. S. 2014. ASSISTAT Version 7.7 beta. Campina Grande-PB: DEAG-CTRNUFCG, 2014. Disponível em http://www.assistat.com. Acesso em: 04/03/2014.

TOMM, G. O.; WIETHÖLTER, S.; DALMAGO, G. A.; SANTOS, H. P. Tecnologia para produção de canola no Rio Grande do Sul. Passo Fundo-RS: Embrapa Trigo, 2009. 39 p. (Embrapa Trigo. Documentos, 113). Disponível em: http://www.cnpt.embrapa.br/biblio/do/p_do113.htm. Acesso em 23/08/2014

VILLAR, J. Evaluación de cultivares de colza en la EEA Rafaela. INTA EEA Rafaela. Información técnica $\mathbf{N}^{\circ}$ 233, 1999. Disponível em: http://rafaela.inta.gov.ar/publicaciones/informac233.htm Acesso em: 14/09/14.

YASARI, M. A. E.; AZADGOLEH, E.; MOZAFARI, S.; ALASHTI, M. R. Enhancement of growth and nutrient uptake of rapeseed (Brassica napus L.) by applying mineral nutrients and biofertilizers. Pakistan Journal of Biological Sciences, Faisalabad, v. 12, p. 127-133, 2009. 